\title{
The Inks of Ancient and Modern Egypt.
}

\author{
By A. LUCAS, O.B.E., F.I.C. \\ (Read at the Meeting, December 7, 1921.)
}

THE profession of scribe in ancient Egypt was one of considerable importance, and the scribe with the implements of his craft is frequently portrayed on the inscriptions in the tombs. In some instances the scribe is shown with a pen behind his ear.

The pens used, as proved not only by the pictures of them, but also by actual specimens which have been preserved, were made from reeds; they were about ten inches long and from one-sixteenth to one-eighth of an inch in diameter, and the end used for writing was bruised to make the fibres flexible (The Mummy, E. A. Wallis Budge, Cambridge, 1894, p. 352). Strictly speaking, however, such an article is a brush and not a pen. Budge states that after the 26 th dynasty (about the 7th century B.c.) the end of the reed was cut like a quill (Budge, loc. cit.). No specimens of this later type of pen exist in the Cairo museum, but the fact that something different from the bruised reed was employed is very manifest from an 
examination of the writing, the difference between that done with a brush and that done with a pen being very marked. A noteworthy example of fine pen work is the illustrated account of the Weighing of the Soul exhibited in the Cairo museum. This is on papyrus and is of Ptolemaic date (B.c. 305 to B.c. 30).

A broad reed with the end cut and shaped like a steel pen is employed to some extent in Egypt and the East at the present day. The date of the first use of ink in Egypt is not known, but Flinders Petrie is stated to have discovered a papyrus bearing written characters as old as 2500 B.c. (Ency. Brit., 1910, Vol. XIV., Article "Ink").

Inkstands containing dried ink have been discovered in the tombs, and generally the ink is of two colours, black and red, though yellow, blue, green and white have also been found. Colours other than black and red, however, were employed by the artist for illustrated scenes and not by the scribe in writing. The red ink was used at the beginning of a subject and for the division of certain sentences. The black ink is always described as being made from carbon, and it is stated that the red is oxide of iron and the blue and green copper compounds, the mineral matter being suspended in water by means of gum (Budge, loc. cit., p. 352). The composition of the various inks is probably as stated, the black being most certainly carbon, but only one record of any scientific examination or chemical analysis can be traced. This is by J. Wiener in his account of the papyri from the Fayum province of Egypt in the collection of the grand duke Rainer (Die Faijumer und Uschnuineiner Papiere, J. Wiener, Mittheilungen aus der Sammlung der Papyrus Erzherzog Rainer, Wien, 1887, pp. 239, 240), which date from the 3 rd to the 7 th century A.H. (9th to 13 th century A.D.). Wiener states that the papyri referred to are written with two different kinds of ink, one a carbon ink and the other an iron ink. The carbon ink is black and is not affected by the action of hydrochloric acid, nitric acid or chromic acid. The iron ink is brown, and gives a blue coloration with hydrochloric acid and potassium ferrocyanide. Schubart also mentions two kinds of ink used on papyrus, one very black and one brown, which latter he states is found about four centuries A.D., but the nature of the ink does not appear to have been determined (Einführung in die Papyruskunde, W. Schubart, Berlin, 1918).

Through the kindness of several friends. I have been enabled to examine various specimens of ancient Egyptian ink. I am indebted to Mr. Quibell, the Curator of the Cairo Museum of Antiquities, for a small quantity of black ink taken from an inkstand of the time of Amenhotep III. (16th century B.c.), which means that the ink is almost 3500 years old. I am also indebted to Mr. Quibell for several potsherds bearing written inscriptions and for fragments of papyrus and parchment documents. Mr. C. C. Edgar, Inspector of the Department of Antiquities, Cairo, has also been good enough to give me fragments of papyrus and parchment. These specimens will now be described.

DRIED INK.- The total weight of this was $0.05 \mathrm{grm}$, and of this a part consisted of sand, which had become mixed with the ink probably in the tomb. The ink was first treated with ether, which, however, failed to extract any 
colouring matter; it was then ground up with water and the sand separated by decantation. The residue was black; it burnt like carbon; it was not bleached by a solution of sodium hypochlorite, and gave negative tests with all the other reagents applied: when strongly heated in a small tube with lead chromate, it gave off a gas which turned lime water milky, and it was therefore undoubtedly carbon. The remains of the powder were eventually mixed with gum and water and used for writing. The writing, when tested for iron, gave negative results.

Potsherds.-Papyrus was a government monopoly and was expensive, and cheaper materials, therefore, such as fragments of broken earthenware vessels (known as Ostraka) and pieces of stone were frequently employed instead. The ink on all the potsherds seen in the Cairo museum and on the few pieces examined is black in every case, though writing on Ostraka in red is not unknown. The writing examined was not bleached by sodium hypochlorite and was destroyed by heating, and the ink is certainly carbon.

PAPYRUs.-The specimens of papyrus examined date from Roman times (30 B.C. to A.D. 395 ) to the 9 th century A.D. The ink is largely black, but in a few cases is brown, though not a very definite brown. The black was not bleached by sodium hypochlorite, and gave negative results with all the other reagents employed, and is therefore carbon. The brown gave similar negative results to the black.

Parchment.- Some of the specimens are undated, while others vary in date from the 7 th to the 12 th century A.D. The ink in all instances is brown, and gave the reactions for iron when tested with potassium thiocyanate, potassium ferrocyanide and with caustic soda, and therefore is an iron compound and not carbon. In the case of two manuscripts dated 609 and 620 respectively of the Coptic era (A.D. 893 and 904), which were shown to me by Mr. Henri Munier (the Librarian of the Department of Antiquities and author of the volume on Coptic Manuscripts in the general catalogue of the museum), but which I was unable to test, the ink was very brown and had all the appearance of being an iron ink.

If the date of the earliest specimen tested which is given as the 7 th to 8 th century A.D. be accepted, then iron ink was known and used at that time, which is several centuries earlier than is generally supposed.

Old ARABIC AND Coptic Books.-I have also had an opportunity of examining the ink in several old Arabic and Coptic books. These are as follows:

A. An account book written in Arabic and dated 1181 A.H. (A.D. 1767) received from the Government Archives, Cairo.

The ink in this book is of two colours, one being that in which the body of the book is written and the other that used for certain notes and totals of figures. The former is generally black, but where the film of ink is thin, the colour is grey with sometimes a slight suggestion of brown. The ink of the notes and of many of the totals is brown, but this brown is largely, though not entirely, due to the fact that the ink lines are partly covered with scales of a brown glittering material which, under the microscope, are suggestive of mica, and which are almost certainly 
the remains of the powder used to dry the ink. Both inks are carbon, and both give a slight reaction for iron.

B. An account book written in Arabic and dated 1216 to 1218 A.H. (A.D. 1801 to 1803 ) received from the Government Archives, Cairo. The ink in this book is largely of a dark-grey colour. It is a carbon ink, and gives a slight reaction for iron.

C. A portion of the Old Testament written in Arabic and bearing the Coptic date 1028, which corresponds to A.D. 1312 .

This book has manifestly been repaired at some time and the paper of a number of pages at each end is newer-looking and of a different quality from that of the rest of the book. The ink in the greater part of the book is brown, and is an iron ink, but on some pages the ink is black and is carbon. This carbon ink contains sufficient iron to give the usual reactions when tested. On the newer pages at the ends of the book the ink is also in some instances an iron ink which has turned brown and, in some cases, a carbon ink which is black.

D. A large prayer book written in both Arabic and Coptic which unfortunately is undated, but which is manifestly old.

The ink as a rule is a very good black with occasionally a little grey where the film is thin. There is a slight suggestion of brown on a few pages. The ink is a carbon ink which, however, contains a little iron. At the end of the book there are a few separate pages of a slightly smaller size, the paper and ink of which are on the whole similar in appearance to those of the body of the book, but occasionally the ink is slightly brown. The ink, whether black or brown, is carbon except for that used for an ornamentation at the beginning of the separate pages, which is brown and is an iron compound.

$E$. A small prayer book written in both Arabic and Coptic, which unfortunately is undated, but which undoubtedly is old.

The ink is brown and is an iron compound. In many places there are holes in the paper along the ink lines caused apparently by some corrosive agent in the ink. Haerting states that this effect is not due to acid, but to the fact that ferric oxide is produced and forms a brittle mass of small crystals with cellulose* (Haerting, Kolloid Zeitsch., 1919, 25, 74-79; Chem. Abstr., 1920, 886).

For the Bible and prayer books, I am indebted to Abdu Effendi Yussef, of the Government Analytical Laboratory, Cairo.

The paper of the books mentioned has been examined and is linen in each of the five cases.

One point already mentioned requires special consideration, namely, the fact that carbon ink is sometimes brown. This was first stated in my book on Legal Chemistry published in 1920, and the following facts may be given in support of this statement:

(1) That the ink on many old manuscripts which are dated earlier than

* A coarse woven fabric in the Cairo museum on which there is writing in large characters, the ink being now brown, shows this corrosion along the ink lines in a ver $\mathrm{y}$ marked manner. 
any known use of iron ink is sometimes brown.* Thus, the ink on manuscripts of papyrus exhibited in the Sultania Library, Cairo, and dated between A.D. 622 and A.D. 719 is brown in some instances, as is also the ink on manuscript Korans exhibited in the same library and dated between A.D. 719 and A.D. 912.

(2) That ink which has been tested and found not to be an iron compound is brown or partly brown (Legal Chemistry, A. Lucas, p. 81; also the present communication).

It is true that, in many instances, the ink which has become brown has not been tested, but in view of its age and of the fact that in some cases only part of the ink on any one page or even part of a word or letter is brown, the rest being black, whereas iron ink becomes wholly brown, and in view too of the further fact that in a few instances the ink has been tested and proved not to be an iron compound, it must be accepted that what has been originally a black ink of the carbon type does sometimes become brown. This, at first sight, seems extraordinary and even impossible, since one of the characteristics of carbon is its black colour and unalterability, carbon ink being always regarded as the best type of a permanent black ink.

In this connection, it may be mentioned that Lehner states that "most European-made Indian inks are distinctly brown when diluted to any great extent" (S. Lehner, Ink Manufacture, London, 1914, p. 119).

It is of course not contended that ink in which such a colour change as that described has taken place was ever a good quality of carbon ink, for this is manifestly not the case, since many carbon inks of very early date are still an intense black, and could not have been blacker even when first employed. It is stated, however, that some ink now brown is not an iron compound, but has been originally a black or practically black ink of the carbon type, and that it has become brown. How then is this colour change to be accounted for? Before offering any suggestion as to the cause of this change, I would mention the fact that while the best quality of carbon for ink is obtained as a deposit during the partial combustion of organic materials such as oil and resin, there are other methods of manufacture which must give a product of very inferior quality. Thus, in an old Arabic book in the Sultania Library, Cairo, unfortunately anonymous and undated, there is a recipe for making carbon ink, which is to take date stones, put them in an earthenware vessel stoppered with clay, heat the vessel for about twenty-four hours, then allow it to cool, grind and sift the contents, and make into ink with gum and water. Such an ink would be of poor quality, and would contain very little free carbon. As an example of a good quality carbon ink, the method of manufacture kindly supplied by a priest of the Coptic Church may be mentioned. $\dagger$ The recipe is as follows: Put a quantity of incense on the ground, and round it place three stones or bricks, and resting on these an earthenware dish, bottom upwards, covered with a damp cloth; ignite the incense.

* The use of iron ink would seem to be older than is generally supposed, and it is at least as early as the 7 th or 8th century A.D., and if it can be shown to have been employed as early as A.D. 622 , this argument is no longer valid.

† Through Abdu Effendi Yusef, of the Government Analytical Laboratory. 
Carbon is formed and is deposited inside the dish, from which it is removed and made into ink by mixing with gum arabic and water.

The suggestion put forward as a possible explanation of the colour change from black to brown in a carbon ink is that the ink has contained very little free carbon in the first place, but has contained compounds, possibly of a tarry nature, which have turned brown, and also, in some cases, a small proportion of iron compounds, which have also turned brown, and that this brown colour has masked any small amount of carbon present. In some instances, the carbon of the ink may have been rubbed off the paper, leaving a brown stain due to a small proportion of some ingredient other than carbon that was present.

Irvine states that carbon black made from natural gas contains bodies of a dirty brown colour which show as a kind of halo surrounding the letters when the black is used for printing ink.* Some such bodies may be present in carbon produced by other methods than from natural gas.

The modern Egyptian inks comprise carbon ink, iron-gall ink and aniline ink, and may either be imported or made locally. A number of different specimens of carbon ink have been tested with the following results:-

SAMPLE.
A. Marked: Best black writing ink, Tabrizy per 100 c.c.

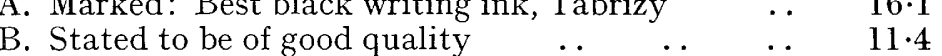
Ger 100 c.c.
C. Stated to be of fair quality
...
$12 \cdot 0$
D. Stated to be of best quality, Turkish
.
$13 \cdot 5$
E. Marked like "A." Stated to be of first quality ..
$14 \cdot 6$
$2 \cdot 9$
F. Marked like "A." Stated to be of second quality
$14 \cdot 1$
$1 \cdot 3$
G. Stated to be of ordinary quality $\ldots \quad \ldots \quad$..
$8 \cdot 9$
$1 \cdot 2$
$1 \cdot 2$

Total Solids.

Ast. Grms.

The first three samples were kept in the original bottles in the laboratory for eight years, and were then re-examined. In each case there was a deposit of carbon at the bottom of the bottle. "A" was still a fairly good black ink; both "B" and " $C$ " were acid, and had a disagreeable smell, due apparently to decomposition of the gum; "B" gave a very thin, poor, grey writing; while " $C$ " was of a light brown colour, and contained no carbon at all, the whole of the carbon having been deposited in the bottle. The results of the analysis were as follows:-

Sample.
$\left.\begin{array}{l}\text { Total Solids. } \\ \text { Grms. per } 100 \mathrm{c.c} . \\ \text { A } \\ \text { B } \\ \text { C }\end{array}\right\}$ after 8 years

The writing made with all the seven specimens of ink enumerated was tested for iron in the usual way. "A" gave a very slight reaction, "B" and " $\mathrm{C}$ " also. gave a slight reaction, but more marked than "A," while " $D$," " $E$ " and " $F$ " gave no definite reaction.

Government Analytical Laboratory, CaIRo, Egypt.

* On the Preparation of Carbon Black from Natural Gas in America. R. Irvine. J. Soc. Chem. Ind., I894, P. I31. 


\section{Discussion.}

Mr. J. F. BLIGHT said he would be interested to have some information about the quality of the material upon which the ink was used. In some cases the material was other than papyrus, and he wondered whether this would account for the variation of tint in the colour of the writing, which was a point dwelt upon by the author.

Mr. T. TICKLE mentioned that he had noticed on specimens of paper 3000 years old that some of the strokes were more glazed than others, and he wondered whether this was due to old or new gum arabic, or whether this was material in which carbon was suspended.

Mr. Chaston Chapman enquired what condition of iron caused the red colour, and whether tannin had been used.

Mr. A. More stated that there were two iron inks-red iron oxide (rouge) and black iron tannate, but questioned whether the red on some of the specimens shown might not be due to cinnabar.

Mr. C. A. Mrtchell, replying for the author of the paper, said the matter was of importance from a practical point of view, apart from the antiquarian interest, since carbon inks were used not only for writing, but also sometimes in forged documents to make modern ink appear old. He was indebted to Mr. Lucas for the opportunity of examining the original specimens shown to the meeting, and could confirm all the results. It was interesting to note that some of these inks contained not only carbon but also iron, probably derived from impurities in the vegetable material from which they were prepared, and not from the paper on which they were written, since the paper only gave a faint reaction for iron. The brown colour was probably due to impurity in the carbon, for lampblacks always contained more or less oil, soluble in ether, and in the case of certain commercial samples this might be as high as 8 per cent. The quality of the material could not have had much influence on the colour in the specimens exhibited, since in some places the ink was a good black, and in other places quite brownso that the difference was due to the ink rather than the material. The glazed appearance of some of the strokes of the specimens exhibited was probably due to the gum or other medium with which the original carbon had been mixed; in other cases talc was present. In answer to Mr. Chapman's question, the speaker remarked that the iron was probably originally in combination with tannin ; and the examples to which Mr. Lucas had referred were, probably, the first known instances of the use of an iron tannin ink. The inks used in the manuscripts recently unearthed in Westminster Abbey_dating back to 700 or 800 A.D.- were in all probability carbon inks. 